\title{
Correction to: The effect of Triaenophorus nodulosus (Cestoda: Bothriocephalidea) infection on some biochemical parameters of the liver of Perca fluviatilis
}

\author{
Ekaterina V. Borvinskaya $^{1}$ - Irina V. Sukhovskaya ${ }^{1} \cdot$ Lev P. Smirnov ${ }^{1} \cdot$ \\ Albina A. Kochneva ${ }^{1}$ - Aleksey N. Parshukov ${ }^{1}$ Marina Yu. Krupnova ${ }^{1}$. \\ Elizaveta A. Buoy ${ }^{1} \cdot$ Rimma U. Vysotskaya $^{1} \cdot$ Maria V. Churova ${ }^{1}$
}

Published online: 29 October 2019

(C) Indian Society for Parasitology 2019

\section{Correction to: J Parasit Dis \\ https://doi.org/10.1007/s12639-019-01128-0}

In the original publication of the article, 'Project No. 0218-2019-0076' and 'KarRC RAS' are missing and the list of e-mails does not include the e-mail of the first author-Ekaterina V. Borvinskaya (borvinska@gmail.com). Hence, the authors would like to correct the same which are mentioned below.

The original article can be found online at https://doi.org/10.1007/s12639-019-01128-0.

Albina A. Kochneva

kochnevaalbina@gmail.com

Ekaterina V. Borvinskaya

borvinska@gmail.com

Irina V. Sukhovskaya

sukhovskaya@inbox.ru

Lev P. Smirnov

levps@rambler.ru

Aleksey N. Parshukov

aleksey.nik.parshukov@gmail.com

Marina Yu. Krupnova

mukrupnova@rambler.ru

Elizaveta A. Buoy

elizaveta.vdovichenko@gmail.com

Rimma U. Vysotskaya

rimma@bio.krc.karelia.ru

Maria V. Churova

mchurova@yandex.ru

1 Institute of Biology at Karelian Research Centre of Russian Academy of Sciences, 11 Pushkinskaya Street, Petrozavodsk, Russia 185910
The list of e-mails does not include the e-mail of the first author of the article-Ekaterina V. Borvinskaya (borvinska@gmail.com).

Acknowledgements The study was carried out under state order KarRC RAS Nos. 0218-2019-0076 and 0218-2019-0075 and was cofinanced the Russian Foundation for Basic Research, Project No. 17-04-01700 a. The research was carried out using the equipment of the Core Facility of the Karelian Research Centre of the Russian Academy of Sciences. 